\title{
A Sociologia das Cozinhas - usos, práticas sociais, relações de gênero e de trabalho no cotidiano da cozinha das casas
}

\author{
Ana Cláudia Bessa ${ }^{1}$ \\ Recebido em março de 2021 \\ Aceito em junho de 2021
}

\begin{abstract}
RESUMO
Este artigo se baseia em um trabalho proposto em sala de aula para a graduação em Sociologia. O tema da pesquisa abrangeu as relações sociais que se estabelecem nas cozinhas das casas a partir de paralelos entre o universo doméstico e o comportamento social, cruzando perspectivas diferentes para analisar um contexto que pode produzir tanto a subalternidade, como o protagonismo feminino. A pesquisa exploratória de pequena abrangência foi realizada através de um survey online que forneceu dados que permitem um direcionamento ao desenvolvimento de novas hipóteses a respeito do ambiente doméstico com suas relações sociais e de parentesco. Os resultados permitiram considerações sobre a importância da casa como elemento central das relações, das representações e das reproduções sociais dos papéis masculinos e femininos no cotidiano. As respostas revelaram que há um campo a ser explorado nos estudos das relações sociais que se estabelecem a partir da cozinha das casas, que vão além das relações de parentesco e avançam para questões de gênero, dominação e divisão sexual do trabalho.
\end{abstract}

Palavras-chave: Cozinha; Gênero; Divisão Sexual do Trabalho; Sociologia.

\section{The sociology of kitchens - social uses and practices, gender and work relationships in the everyday use in the kitchen of the houses}

\begin{abstract}
This article is based on a work proposed in the classroom for undergraduate sociology. The research theme covered the social relationships that are established in the kitchen of the houses from parallels between the domestic universe and social behavior, crossing different perspectives to analyze a context that can produce both subordination and female protagonism. The exploratory research of small scope was carried out through an online survey that provided data that allow the development of new hypotheses regarding the domestic environment with its social and kinship relationships. The results allowed considerations about the importance of the house as a central element of relationships, representations and social reproductions of male and female roles in everyday life. The answers revealed that there is a field to be explored in the studies of social relations that are established from the kitchen of the houses, which go beyond kinship relations and advance to issues of gender, domination and the sexual division of work.
\end{abstract}

Keywords: kitchen; gender; sexual division of labor; sociology.

1 Graduanda em Sociologia pela Universidade Federal Fluminense (UFF). E-mail: nabessa.uff@gmail.com. 
Este trabalho se originou nas aulas da disciplina Ambiente e Sociedade ${ }^{2}$ para a graduação no curso de Sociologia da Universidade Federal Fluminense (UFF). A ideia de ambiente é uma forma de olhar as questões sociais pela dimensão espacial ou de localização onde os indivíduos se encontram. Mesmo tendo consciência das limitações dos dados produzidos, para um breve trabalho de final de disciplina, a pesquisa buscou através de conceitos abordados pela Sociologia, desenvolver estudos no campo das Ciências Sociais para construir uma análise que integre a teoria e um estudo de caso, usando a cozinha como objeto de pesquisa.

O trabalho teve o objetivo de ser um estudo exploratório. Gil (2008) define que os estudos exploratórios partem de pesquisas em processos menos rígidos que podem ser a formulação de hipóteses pesquisáveis para estudos posteriores. A metodologia escolhida foi a pesquisa quantitativa, através do uso de um survey online. O formulário foi construído utilizando a ferramenta Google Forms ${ }^{3}$ e distribuído na rede social Facebook. Contudo, a partir da utilização dos dados para debater a teoria, e considerando a forma como os dados são usados e apresentados, a pesquisa que se iniciou como quantitativa, acabou por se caracterizar como qualitativa.

O trabalho se baseou em um questionário de opinião e comportamento sobre os usos e práticas da cozinha no cotidiano das casas - que foi disponibilizado pela Internet em novembro de 2019 para pessoas maiores de 18 anos (sem necessidade de se identificar) que desejassem participar espontaneamente da coleta de dados. $\mathrm{O}$ formulário digital continha questões relacionadas a pessoa respondente e a sua casa, em especial a cozinha. As primeiras questões eram referentes ao perfil dos/as respondentes - como idade, gênero, cor ou raça, escolaridade, ocupação, orientação sexual, local de nascimento e moradia. A segunda parte continha questões sobre a casa

\footnotetext{
2 Ementa da disciplina "Ambiente e Sociedade": O curso tem o objetivo de discutir algumas das formas pelas quais o "ambiente" vem sendo tematizado pelas ciências sociais. "Meio ambiente", "espaço", "natureza”, "terra”, "território", "moradia", "casa”, "habitat", "ecologia”, "pluriverso": noções e conceitos como esses são expressivos de como múltiplas perspectivas e subcampos disciplinares colocam no centro de suas preocupações os ambientes enquanto lugares de vida e/ou lugares em que se vive.

${ }^{3}$ Google forms é uma ferramenta digital disponibilizada pela empresa Google para criar questionários para a realização de pesquisas pela Internet. Disponível em <https://www.google.com/intl/ptBR/forms/about/>. Acessado em 10 out. de 2019.
} 
e a cozinha - como quantidade de cômodos, de moradores e quem reside na residência, se possuem mesa de refeições fora da cozinha, onde são feitas as refeições e etc. $\mathrm{Na}$ terceira parte constavam questões relacionadas aos usos e rotinas da convivência dentro da casa e da cozinha - quem usa a cozinha, como os espaços são utilizados, quanto tempo ficam neste cômodo, etc. Na parte final, o questionário procurava saber sobre os sentimentos relacionados a cozinha - se sabe/costuma/gosta de cozinhar, sobre lembranças de infância neste cômodo da casa, o que mais/menos gosta, etc.

Apesar de ter sido um questionário disponibilizado por pouco tempo, a quantidade de participantes foi relevante e foi nítida a percepção de interesse e satisfação das pessoas em responder a uma pesquisa com este tema. O tema evidenciou sentimentos de familiaridade e pertencimento nos/as respondentes e muitos fizeram questão de expressar o quanto gostaram de participar da pesquisa. Essas manifestações foram feitas diretamente à graduanda/pesquisadora em virtude da distribuição do questionário ter sido feita pelo perfil pessoal no Facebook. Esse retorno, inclusive, evidenciou que o questionário poderia ter tido um espaço para este tipo de feedback espontâneo em caso de os/as respondentes desejarem dizer algo mais a respeito da pesquisa. Este espaço seria uma forma de registrar esses depoimentos e também integrar estas manifestações como dados empíricos fornecidos pela pesquisa. Ademais, torna-se imperativo mencionar que o trabalho se tornou mais prazeroso e gratificante em decorrência dessas manifestações.

\section{O questionário e o perfil dos/as respondentes}

O questionário continha 37 perguntas que investigaram sobre o perfil dos/as respondentes, sobre suas casas, sobre as pessoas que convivem na casa, sobre as rotinas domésticas e sobre a cozinha. Conforme já mencionado, as pessoas que participaram da pesquisa foram acessadas através das redes sociais, a partir do perfil pessoal da graduanda no Facebook. O convite para participar da pesquisa incluiu um pedido para que os/as amigos/as repassassem o mesmo aos seus contatos, fazendo com que a pesquisa fosse divulgada para outros círculos de relacionamento. O questionário foi 
disponibilizado por 15 dias e respondido por 247 pessoas. A decisão de interromper a coleta de dados foi tomada em função da data final para entrega do trabalho. Por se tratar de um trabalho para final de disciplina, não haveria disponibilidade de tempo para análise de um volume muito grande de dados.

As características principais do perfil dos/as respondentes revelaram que a maioria das pessoas que participou da pesquisa é do gênero feminino (90,2\%), da raça ou cor branca $(64 \%)$, têm entre 21 e 40 anos de idade $(46,15 \%)$, heterossexuais $(85,8 \%)$, moram em apartamento (51\%), possuem emprego formal (43,7\%) e possuem escolaridade superior completa (43,7\%). Desta forma, temos um perfil de mulheres que vivem em centros urbanos, com boa escolaridade, com participação efetiva no mercado de trabalho e de uma faixa etária que corresponde à idade média em que as mulheres se casam, que é de 29 anos, segundo IBGE(2019) ${ }^{4}$.

Desta forma, é digno de nota, compreender que as características de perfil declaradas pelas respondentes neste trabalho apresentam um recorte de raça e de classe significativo que pode produzir resultados que exclui outras realidades femininas como as referentes às mulheres negras e também às mulheres pobres, por exemplo. Essa observação é relevante porque a questão racial, a falta de acesso à educação e a exclusão do mercado de emprego formal são realidades que produzem contextos diferentes dentro da perspectiva social, mesmo levando em consideração o fato de que este trabalho se resume ao ambiente doméstico.

\section{A cozinha}

A busca por definir uma casa pode ser bem ampla. A casa não é somente um lugar, ou onde se habita. A casa faz parte da constituição dos indivíduos, produz significados, materializa sentimentos, realizações e relações sociais. A partir da casa são centralizados muitos processos de constituição individual e coletiva, dos âmbitos público e privado.

\footnotetext{
4 Ver dados no site do Instituto Brasileiro de Geografia e Estatística - IBGE. Disponível em $<$ https://www.ibge.gov.br/estatisticas/sociais/populacao/9110-estatisticas-do-registro-

civil.html?=\&t=resultados $>$. Acesso em 10. jun. de 2020.
} 
A etnografia evidencia que a casa existe na medida em que está inserida em uma configuração de casas e que, em ambas, as relações se organizam ao integrar dois princípios distintos de "conectividade" (relatedness): "sangue" e "consideração". Ademais, a existência relacional da casa e da configuração de casas está vinculada à coexistência e integração mútua de esforços de individuação e de processos relacionais (MCCALLUM; BUSTAMANTE, 2012).

A pesquisa demonstrou que a moradia é o lugar onde se vive e convive. A casa é o local primordial da convivência social onde se desenvolvem práticas e modos de vida. Cada família concebe subjetivamente seu lugar no mundo, seus espaços e suas formas de viver em dinâmicas diversas que podem ser vistas a partir da cozinha das casas. Deste modo, não se pode falar de ambiente e sociedade, ou de relações sociais, sem falar da casa. E dentre todos os cômodos que tem uma casa, não se pode deixar de analisar a cozinha como o cômodo onde se desenvolve grande parte das relações sociais primárias entre as pessoas.

Pensando nas relações que se estabelecem dentro deste cômodo, que é comum à maioria das casas, uma das perguntas da pesquisa foi exatamente essa: Onde você mora tem cozinha? Isso porque, apesar de parecer óbvio, é importante saber se as pessoas respondentes tinham cozinha em suas casas. Esta também foi uma forma de comunicar aos participantes da pesquisa, a que objeto de estudo a mesma se refere e também para certificar que a pesquisadora está se comunicando com o público correspondente. Em uma pesquisa online, isso se torna mais importante ainda para validar o método de pesquisa digital que ainda cria certa resistência entre alguns/mas pesquisadores/as. A resposta não surpreendeu: 100\% dos/as respondentes declararam ter cozinha em sua casa. Ou seja, todas as pessoas que responderam à pesquisa partilham da convivência dentro de uma cozinha em alguma parte de seu dia.

Essa também é uma realidade das cozinhas: elas fazem parte de nosso cotidiano, não apenas existem dentro das casas. A pesquisa revelou que mais de $80 \%$ dos/as respondentes considera que a cozinha é importante para eles/as e quase $50 \%$ dos/as respondentes disseram que cozinham todos os dias em sua casa. Sendo, a cozinha de uma casa o local onde se preparam os alimentos, é lá que se dão atividades funcionais fundamentais, uma vez que a alimentação é uma necessidade básica de 
sobrevivência humana. Isso torna a cozinha um espaço de uso compartilhado por todos. Tanto os indivíduos de dentro da casa, como os de fora da casa, usufruem desse espaço doméstico.

Mas a cozinha também é mais do que isso. A cozinha é um local onde se desenvolvem relações sociais e familiares, de confraternização, convivência e conflitos. Relações que unem trabalho, cultura e prazer. As próximas seções deste artigo, apresentarão um paralelo entre as respostas do questionário e conceitos sociológicos. Este paralelo teve por base estes apontamentos de forma a olhar para as características que revelaram a cozinha como um lugar de construção de significados nas relações humanas e sociais. Então, vamos para a cozinha!

\section{As relações de gênero dentro da cozinha}

A pesquisa revela uma informação importante: a cozinha ainda é lugar de mulher. É possível fazer essa afirmação a partir de várias respostas dadas na pesquisa, bem como também a partir de interpretações que podem ser dadas a essas respostas. Uma observação, e de onde se pode partir, reside na constatação de que entre os/as respondentes da pesquisa, 90,2\% declararam ser do gênero feminino. Como forma de análise, será considerado este número absoluto, mesmo sabendo que não houve controle sobre a quantidade de homens e mulheres que receberam a pesquisa para responder. Isso é importante porque o número de homens que tiveram acesso ao questionário pode ser menor que o número de mulheres. Por outro lado, pode-se também interpretar que esse número menor pode indicar que, pelo fato da pesquisa ser espontânea, menos de $10 \%$ dos que tiveram acesso à pesquisa, e se interessaram espontaneamente - em participar de uma pesquisa sobre cozinha, eram do gênero masculino. Ou ainda, que ao repassar a pesquisa, por ser da cozinha, as próprias mulheres repassaram para outras mulheres. De qualquer modo, a maior prevalência do gênero feminino pode dar a entender que - seja porque menos homens se interessaram ou porque mulheres repassaram a outras mulheres - a cozinha é um cômodo da casa que ainda não contempla a diversidade de gênero.

Outra consideração pertinente a respeito da presença feminina na cozinha das 
casas é pensar sobre a presença feminina nas cozinhas profissionais. A diferenciação entre a cozinha doméstica e a cozinha profissional também apresenta uma divisão sexual do trabalho e um recorte de gênero. Segundo uma pesquisa rápida na Internet, só existe uma Chef de cozinha premiada no Brasil - em um total de 18 profissionais com as estrelas do guia Michelin em 20195. Sendo assim, o ambiente da cozinha doméstica - predominantemente feminino - não se reproduz nos ambientes de gastronomia que são considerados profissionais.

A cozinha profissional é um ambiente muito masculino. A cozinha de elite ou alta cozinha construiu-se estrategicamente em torno de chefs homens. Quando esse tipo de manifestação gastronômica deixou o espaço do privado para ocupar a esfera pública, o ambiente doméstico e os postos na cozinha doméstica foram designados às mulheres, que já eram desde há muito as responsáveis pelo cuidado com a alimentação de suas famílias (BORBA, 2015, p. 107).

Outra resposta destacada é a observação de que 90\% das pessoas que responderam à pesquisa, disseram que sabem cozinhar. Os saberes culinários são um capital cultural importante que se transmite entre gerações. Além de saber cozinhar, $75 \%$ dos/as respondentes disseram que gostam de cozinhar. Ou seja, o estar dentro das cozinhas não é apenas uma questão de necessidade, existe um prazer em estar dentro dela. Efetivamente, as pessoas se relacionam afetivamente com a cozinha.

Por outro lado, se for considerada a informação de que mais de 90\% das respondentes da pesquisa são mulheres e que há uma questão de gênero relacionada à presença majoritariamente feminina nos trabalhos domésticos, temos que pensar obrigatoriamente sobre o quanto o papel de gênero impõe às mulheres que saibam cozinhar. A divisão sexual do trabalho também pode confundir obrigações/necessidades e preferências/prazer. Essas diferenças entre preferências e obrigações podem configurar, não somente o trabalho doméstico feminino não

\footnotetext{
${ }^{5} \mathrm{O}$ Guia Michelin é um guia gastronômico de relevância mundial. Os restaurantes são avaliados com uma, duas ou três estrelas. No Brasil, em 2019, 18 restaurantes foram premiados com as estrelas Michelin, o que confere significativo prestígio aos/às chefs que os comandam. Ver mais sobre o guia em $<$ https://guide.michelin.com/br/pt_BR $\geq$. Sobre os restaurantes estrelados em 2019, ver mais no link: $<$ https://paladar.estadao.com.br/noticias/restaurante-e-bares,guia-michelin-2019-confira-osrestaurantes-estrelados-em-sp-e-no-rj,70002818173>. Links acessados em 20 jul. de 2020.
} 
remunerado, como a precarização persistente do mercado de trabalho para as mulheres. Outra indicação é o fato de que as mulheres ainda são as maiores responsáveis pelos cuidados familiares.

\begin{abstract}
Note-se que a inserção das mulheres no mercado de trabalho brasileiro tem sido caracterizada através do tempo pela marca da precariedade que tem atingido uma importante parcela de trabalhadoras. Mesmo que os dados sinalizem para um decréscimo relativo desse contingente na década de 90, ainda assim, em 1998 nada menos que $36 \%$ da força de trabalho feminina ou 10 milhões de mulheres situavam-se em nichos precários do mercado de trabalho, seja como trabalhadoras domésticas, seja realizando atividades não remuneradas ou trabalhos destinados ao consumo próprio ou do grupo familiar (BRUSCHINI; LOMBARDI, 2016, p. 174).
\end{abstract}

A oposição entre cultura e natureza é estruturante do ser humano. Resumidamente, a cultura é aquilo que o homem modifica e a natureza aquilo que ele recebe pronto. O trabalho se organiza a partir dessa oposição, uma vez que o trabalho é produzindo pela interferência do homem sobre a natureza. Além disso, há também as diferentes concepções daquilo que é considerado trabalho. Ou seja, a forma como a sociedade se relaciona culturalmente com seu ambiente pode contribuir também para entender as relações que se estabelecem dentro das casas, e das cozinhas. $\mathrm{O}$ trabalho doméstico e a divisão sexual do trabalho são questões que se encaixam neste debate de oposição entre cultura e natureza, uma vez que são fatores que contribuem para organizar a vida social de homens e mulheres.

O desenvolvimento da ciência, dos processos tecnológicos e produtivos, carregam consigo esta construção do trabalho e controle da produção. Este controle que os indivíduos fazem de seu ambiente, caracteriza-se por essa oposição entre cultura (desenvolvimento) e natureza (primitivo), masculino (conhecimento) e feminino (selvagem), o domínio (cultura) que controla a submissão (natureza). Estes conceitos estão imbricados com a industrialização e o colonialismo que são constituídos de um patriarcado composto invariavelmente por uma visão machista de mundo (SHIVA, 200o). Essas práticas, carregadas de simbolismos, são utilizadas em diversas esferas da vida social. As relações que se estabelecem no ambiente doméstico, nos usos das cozinhas e na desvalorização dos trabalhos femininos, também podem ser entendidos a partir desses conceitos que, mesmo quando se parecem distantes, estão 
muito relacionados. Uma forma de ilustrar essa oposição consiste no fato de que o trabalho na rua (considerado masculino) é valorizado, enquanto o trabalho doméstico (considerado feminino) é desvalorizado.

Deste modo, quando perguntado "quem normalmente prepara as refeições da casa no dia a dia atualmente", o questionário obteve uma resposta que evidenciou, mais uma vez, a presença do gênero feminino na cozinha, pois 80\% das respostas indicaram que são as mulheres que fazem este trabalho. Mulheres que podem ser as mães, irmãs, tias, avós, a própria pessoa do gênero feminino que respondeu o questionário, ou ainda trabalhadoras domésticas - estas últimas sempre especificadas como sendo do gênero feminino, conforme já evidenciamos anteriormente.

Continuando na linha de pensamento a respeito de cultura e natureza, não é possível pensar em ambiente e sociedade sem pensar em natureza, cultura e construção de processos históricos. Anne McClintock (2010) traz algumas considerações interessantes sobre o imperialismo e as relações de gênero como políticas - culturais e de poder - que permitem fazer relações com as vivências dentro da cozinha. A autora trata da feminilização do mundo e da natureza como modo em que o ambiente é explorado pelos homens. Os homens, detentores do conhecimento (cultura), como sendo os indivíduos sociais que detêm o poder e os que possuem a natureza (que é feminina). Essa posse compreende a subordinação das mulheres como categoria de natureza. A natureza que pode ser moldada e dominada pelo conhecimento. Isso dá uma boa possibilidade de explicação do motivo pelo qual as mulheres ainda estão tão presentes na cozinha, considerado socialmente como um trabalho inferior, de cuidado, e, muitas vezes, sequer considerado como trabalho. A invisibilidade e a desvalorização são realidades do trabalho doméstico. Assim como a diferenciação, já mencionada, entre a valorização da cozinha profissional (masculina, dotada de conhecimento) em relação à cozinha doméstica (feminina, categorizada como amadora).

A cozinha das casas também é tida como um local de saberes menores, de trabalho braçal e subalterno. Essa é uma concepção capitalista associada aos trabalhos não assalariados, “cuja exploração foi naturalizada” (FEDERICCI, 2017, p. 13). A cozinha ainda pode carregar em si uma diminuição e desvalorização do papel das mulheres, 
reduzindo-as a meios ou ferramentas de trabalho, sem atuação criativa e que agem passivamente de acordo com as demandas que lhe são solicitadas dentro daquilo que abrange a vida privada/familiar/doméstica - sem valor efetivo - nas cozinhas. Uma herança do discurso colonial que permanece nos dias de hoje. Helena Hirata (2002) traz alguns elementos adicionais que ajudam a compor argumentos e pensar as questões de gênero citando as consequências que o modelo normativo traz para as desigualdades globais entre homens e mulheres no mundo do trabalho. São dados que podem ser ferramentas para análise das relações no ambiente doméstico e demonstram que esta é uma situação que apresenta lentidão no que se refere às mudanças, mesmo com a modernidade e a ascensão da mulher no mercado de trabalho. Situação que mantém a mulher ainda muito inserida no universo das tarefas domésticas e do cuidado dentro das famílias.

\footnotetext{
Em oposição a essas tendências recentes no trabalho profissional feminino, as mudanças no trabalho doméstico são menores e muito mais lentas. Se o forte desenvolvimento das tecnologias domésticas tendeu a facilitar essas tarefas, a divisão sexual do trabalho doméstico e a atribuição deste último às mulheres, em realidade, continuou intacta. A relação entre o trabalho doméstico e a afetividade parece estar no centro dessa permanência (HIRATA, 2002, p. 150).
}

Essa diferenciação entre homens e mulheres como herança do discurso colonial, também pressupõe a manutenção da diferenciação entre submissão e dominação, colônia e colonizador. O gênero masculino - o homem - como o grande possuidor e dominador de corpos e de modos submissos de vida femininos. Mary Douglas (1991) emprega essa analogia para expressar uma percepção de ordenamento que objetiva controle e estabilidade nas dinâmicas das relações sociais. São simbolismos e dispositivos que determinam distinções - por exemplo - entre dominador e dominado. Considerando que viver é classificar o mundo, não por acaso, a cozinha das casas ainda é categorizada e classificada como um local feminino, mesmo diante das transformações sociais que já se apresentam na participação da mulher na sociedade e no mercado de trabalho - fora de casa - no século XXI.

Neste ponto, é pertinente trazer a questão racial ao debate, ainda mais considerando que a maioria que respondeu ao questionário se declarou ser da raça 
branca. Quando se fala em inserção no mercado de trabalho, é relevante citar que, nos casos das mulheres negras, essa inserção sempre aconteceu de uma forma ou de outra. As mulheres negras, escravizadas ou livres, sempre trabalharam arduamente nas lavouras ou fora das casas. O conceito de "dona de casa" ou da questão do trabalho doméstico, era uma realidade mais referente às mulheres brancas de classe média. Ainda assim, isso não impediu que as mulheres negras também fizessem trabalhos domésticos. As negras, por trabalharem fora, foram as primeiras a acumular funções de trabalho fora e dentro do ambiente doméstico (DAVIS, 2016).

É possível trazer mais elementos ao recorte de gênero, mesmo a mulher já estando, em alguma medida, bastante inserida no sistema capitalista e presente no mercado de trabalho, fora do ambiente doméstico. As mulheres continuam em um tipo de subordinação, acumulando funções sociais e encarando somadas jornadas de trabalho, sem que isso proporcione realização pessoal ou reconhecimento social. Analisando as respostas da pesquisa e as questões relacionadas ao tema, recordei uma passagem da minha infância, na casa de uma das avós. A casa dessa avó era onde obrigatoriamente a família ia todos os domingos quando eu era criança na década de 70. A casa era uma típica casa do patriarca da família. Mas o registro mais forte que se manteve na memória é da matriarca que recebe a família em sua casa no domingo para almoçar. Assim como na pesquisa, na cozinha dessa casa a presença também era feminina. Uma presença feminina tão forte que também leva a pensar em outra perspectiva possível baseada na relação entre casa e maternidade. A cozinha só tinha a presença da matriarca, das filhas, da empregada doméstica (que era sempre uma mulher) e eventualmente das netas, a quem era ensinado o ritual que unia a família em torno dessa refeição dominical que era servida para todos. Enquanto essa movimentação acontecia em torno da cozinha para o preparo do almoço, as crianças brincavam e os homens permaneciam na sala ou na área externa da casa, confraternizando entre si. Os homens só eram chamados e se encaminhavam para a refeição quando a mesa estava posta. Para as mulheres, era um domingo de muito trabalho em nome da família. Enquanto para os homens, era um dia de descanso e lazer. Uma história que configurava passagens comuns das famílias naquela época e a pesquisa também constata este passado, pois 70\% das respostas indicam que era a mãe 
que preparava as refeições em casa na infância. Em certa medida, a configuração de como essas relações acontecem dentro das casas pode ter mudado, se comparado a tempos passados. Alguma mudança sempre acontece e pode ser percebida na contemporaneidade. Embora não haja intenção de se debruçar sobre estas mudanças específicas neste momento, a cozinha de uma casa permanece - não só se mostrando como um lugar de mulher - como um local de grande demanda de trabalho feminino socialmente invisibilizado.

Por outro lado, é importante entender que essa construção histórica da desvalorização do trabalho doméstico, nem sempre existiu. No passado, a divisão do trabalho entre homens e mulheres era igualmente valorizada na vida em comunidade. E mesmo atualmente, existem sociedades que entendem o papel do trabalho doméstico executado pelas mulheres - que pode ir além dos cuidados com a limpeza, por exemplo - como tão essencial quanto as atividades desempenhadas pelos homens. Essa concepção de supremacia masculina é característica das sociedades capitalistas e da era industrial. A migração do trabalho das casas para as fábricas, trouxe consigo a desqualificação do trabalho doméstico a partir do momento em que a importância econômica - geradora de capital - passou a existir fora deste ambiente pois "como as tarefas domésticas não geram lucro, o trabalho doméstico foi naturalmente definido como uma forma inferior de trabalho, em comparação com a atividade assalariada capitalista” (DAVIS, 2016, p. 230).

Nas outras respostas fica evidenciado que a mulher também está atuando fora do ambiente doméstico. Isso porque 50\% das respondentes têm trabalho fora de casa. As mulheres também estão estudando e obtendo graduação - que lhes capacita a obter trabalho profissional - já que mais de 70\% têm escolaridade superior completa ou maior. Além disso, mais de $30 \%$ das mães das respondentes têm terceiro grau completo, o que é significativo ao olhar para a perspectiva geracional. As mulheres, nessa pesquisa, demonstraram que não estão dedicadas somente ao trabalho doméstico e estão obtendo - de forma crescente - educação formal de alto nível há mais de uma geração. Ainda assim, 50\% declararam que são elas que cozinham em casa, sem dividir esta tarefa com outras pessoas, sendo que menos de 10\% declararam que moram sozinhas. Ou seja, a maior parte dos homens que dividem a moradia, não 
atuam nesta tarefa doméstica. A sobrecarga feminina fica evidente.

\section{As relações familiares dentro da cozinha}

As relações familiares podem ser observadas e analisadas a partir das relações que se estabelecem dentro das cozinhas das casas? Pela divisão sexual do trabalho, já vimos que sim. A cozinha reproduz as inquietantes diferenciações sociais que existem entre os trabalhos femininos e os masculinos. Essas diferenciações, embora não tenha sido intenção de que elas fossem tratadas aqui diretamente, também se estendem às remunerações femininas e masculinas, entre oportunidades profissionais para mulheres e homens, entre carga sexual de trabalho e na valorização e diferenciação entre o que é - ou não - considerado trabalho (BRUSCHINI; LOMBARDI, 2016).

Sob um outro ponto de vista, embora seja uma perspectiva relativamente distante da realidade das mulheres respondentes da pesquisa, Heredia (2013) mostra através da análise do modo de vida camponês como se dá estruturação social a partir das tarefas da família e dentro das casas. Considero importante citar essa diferenciação por ser mais um dado para buscar entender como se deu a construção de papéis na sociedade e, principalmente, dentro do ambiente doméstico. Os papéis - definidos de acordo com o trabalho que executam - também definem o cotidiano das famílias, a estruturação econômica, o desenvolvimento das formações sociais e de organização no ambiente. No texto de Heredia, essas diferenciações giram em torno da terra. Isso porque a terra para o campesinato é o grande valor. A terra é de onde se retira toda a riqueza e de onde o homem "retira o pão". No campo, os trabalhos se dividem entre o roçado e a casa. Sendo o roçado o local de domínio do homem e a casa o local de domínio da mulher. Na perspectiva do campesinato, só é considerado trabalho, a atividade que produz bens de consumo para a família. Sendo assim, só o roçado é trabalho. A casa não produz o bem material, portanto não é trabalho. Deste modo, pode-se ver que o trabalho doméstico, ainda nos dias de hoje, nas áreas urbanas, reproduz essa desvalorização persistente de uma atividade que é designada às mulheres. Partindo desse contexto, podemos fazer alguns paralelos com a pesquisa da cozinha para entender como se dão as relações familiares e de trabalho dentro do 
ambiente doméstico. No questionário, mais de 70\% das respondentes moram com até três pessoas. Sendo assim, se considerarmos famílias nucleares (a maioria expressou que mora com filhos/as e companheiros/as), teremos um grande percentual de casas com 4 moradores - mãe, pai e dois filhos. Um outro dado revela a dinâmica cotidiana dessas famílias posto que a maioria faz suas refeições na sala de jantar, se reunindo mais comumente à noite na cozinha, conforme informado pelos/as respondentes. Levando em conta as demais respostas anteriores, vemos que a sobrecarga feminina se revela novamente, com a demonstração que os demais moradores somente conseguem estar em casa no fim do dia.

Desta forma, voltando ao campo, a rotina da família é também uma tarefa feminina. As decisões e a execução sobre o trabalho da casa são responsabilidades da mulher, em famílias que são, possivelmente, mais numerosas que as desta pesquisa. Ou seja, fazer todo o trabalho da casa para atender a tantas pessoas, é um trabalho pesado. Apesar disso, é interessante observar, como já mencionado, que no campo o valor do trabalho não está na casa. No campo, essa oposição entre casa e terra é que define o que é considerado trabalho e não-trabalho. O valor está na terra e todos os privilégios são dados ao homem porque é ele quem trabalha na terra e portanto, é ele quem produz. O trabalho da mulher, embora pesado e fundamental para a família, não tem valor porque ela não trabalha na terra, a mulher trabalha na casa.

Na pesquisa, em alguma medida, a indicação é a mesma pois o valor está na rua e não na casa, uma vez que as famílias somente se encontram à noite, depois de passar o dia todo produzindo na rua. O trabalho da casa no centro urbano é tão desvalorizado quanto no campo, mesmo que considerado sob perspectivas e realidades diferentes. Inclusive, é importante citar que existe um debate público e jurídico sobre a (des)valorização social do trabalho doméstico e do tempo que ele representa na rotina de quem o executa, sendo geralmente a mulher a pessoa de executa este trabalho.

As mulheres tendem a receber menos que os homens porque trabalham seis horas a menos por semana em sua ocupação remunerada. Porém, como dedicam duas vezes mais tempo que eles às atividades domésticas, trabalham, no total, cinco horas a mais que eles. Ao todo, a jornada das mulheres é de 55,1 horas por semana, contra 50,5 horas deles (VIEIRA, Agência Brasil, 2016). 
Outro dado interessante levantado por Heredia (2013) é que a mulher também pode cumprir tarefas no roçado, além das tarefas da casa que são de sua exclusiva responsabilidade. A mulher, também no roçado, acumula funções sem que isso lhe confira nenhum privilégio, prestígio ou poder. Tal dado diz respeito ao fato de que as relações sociais são moldadas pelo ambiente e pelo contato com o mundo exterior. $\mathrm{Ou}$ seja, o homem que trabalha fora da casa é que detém a hegemonia e a superioridade na relação hierárquica dentro da sociedade, onde também se caracteriza uma condição de dominação social. Pode-se dizer que a mulher tem alguma autoridade sobre o ambiente da casa e da cozinha, o que para muitos pode ser uma interpretação de que a mulher exerce a dominação sob esta perspectiva. Contudo, essa autoridade e dominação perante a sociedade continuam de fato e de direito sendo do homem, enquanto a mulher acumula funções sem que isso lhe confira reconhecimento e valorização equivalentes.

É certo que estes dois contextos se apresentam em ambientes e épocas diferentes. Em boa medida, essas questões que nos ajudam a pensar sociologicamente contextos paralelos que se relacionam. Essa análise ajuda a interpretar, não somente os dados da pesquisa, mas também a construção histórica do papel da mulher na sociedade e no mundo do trabalho, olhando-as a partir das relações que se dão nas cozinhas das casas em ambientes e tempos históricos diversos.

\section{As relações sociais dentro da cozinha}

As perguntas sobre as relações sociais dentro da cozinha são as que mais interessaram para desenvolver a pesquisa. Ao mesmo tempo, foram as mais complexas para analisar e fazer associações de modo que a pesquisa da cozinha fosse útil para pensar os modos de ocupação desse espaço de uso comum e como este espaço é concebido pelos indivíduos que vivem na casa. As perguntas sobre quanto tempo as pessoas ficam na cozinha, quem usa a cozinha, como era a cozinha na infância - entre outras - foram pensadas para tentar dar uma orientação de sentido sobre como as relações se estabelecem dentro deste espaço nas moradias.

Numa observação empírica e sem critério científico, é possível que todos nós 
sejamos capazes de nos lembrar de que é muito comum - seja na nossa casa ou na casa dos outros - que as boas conversas terminem migrando para a cozinha. A pesquisa mostrou isso: $50 \%$ das respostas indicaram que as visitas da casa frequentam a cozinha e que quase $70 \%$ considera que frequentar a cozinha de uma casa configura relação de intimidade entre os donos da casa e as suas visitas. Deste modo, a cozinha é um local também onde as relações sociais internas e externas se constituem e se caracterizam. A cozinha é um espaço da casa que conecta, além dos moradores da casa, amigos, vizinhos, colegas de trabalho e outros parentes. Sob uma perspectiva social e política, as relações se constroem quando se abre a intimidade das cozinhas das casas para aquele que vem de fora.

Deste modo, também usando de observação, pode-se buscar explicações possíveis dos motivos para que essa reunião na cozinha ocorra com tanta frequência: o preparo dos alimentos necessita de tempo e de presença humana para que ele seja executado. E são a presença e o preparo - que demandam tempo - dois dos motivos que levam para a permanência neste ambiente em troca de uma boa prosa, justificando que as relações sociais aconteçam neste ambiente. A cozinha se mostra como o espaço de uso, não só funcional, como coletivo. Não só de atividades práticas, mas também de construção de afetos.

Sobre as características das cozinhas, as respostas revelaram que - mesmo sendo a maioria de tamanho pequeno ou médio - possuem mesa com bancos e/ou cadeiras para que as pessoas se sentem juntas. As respostas indicaram que a maioria das moradas se divide - geralmente - com familiares que se reúnem na cozinha, pelo menos, uma vez por dia, todos os dias. Inclusive, a pesquisa revelou - na pergunta "o que você menos gosta na sua cozinha" - que uma das maiores queixas com relação a este cômodo da casa se refere ao tamanho. A resposta foi que a cozinha poderia ser maior, tanto para caber mais gente, como para caber mais coisas. Resposta essa que trouxe um novo elemento para caracterizar a cozinha: como um lugar onde as pessoas colocam suas coisas importantes, suas preferências, suas conquistas materiais e seu consumo, para além do consumo de alimentos.

As cozinhas têm coisas e essas coisas se referem a outra questão sobre a qual se necessita falar a respeito deste ambiente. Assim como a casa - que sempre tem algo pra 
fazer, consertar ou mudar - a cozinha também nunca está pronta. Sempre há algo a acrescentar e ela está em movimento, construção e transformação, sempre precisando de alguma outra coisa. As respostas revelaram outro dado interessante neste ponto que define, além do tamanho, aquilo que mais agrada e o que menos agrada na cozinha. Para a maioria, os equipamentos que a cozinha possui, e o que ela não possui, entram nesta classificação respectivamente. Esse dado mostra a importância das coisas no ambiente da cozinha e o constante desejo de aquisição de novas coisas, como revelação de realizações pessoais e familiares. A partir desta perspectiva, em alguma medida, é possível pensar em como os espaços se moldam, como as pessoas moldam o espaço e como o espaço molda as pessoas, pois “(...) o mundo que habitamos é composto não por objetos, mas por coisas” (INGOLD, 2012, p. 27). O autor define que a diferença entre coisas e objetos se destaca pelo fato de que os objetos são fatos consumados, enquanto as coisas estão num constante porvir. E prossegue numa passagem que parece "desenhar" totalmente a cozinha e seu uso cotidiano pelas famílias pela perspectiva das coisas: "A coisa, por sua vez, é um 'acontecer', ou melhor, um lugar onde vários aconteceres se entrelaçam. Observar uma coisa não é ser trancado do lado de fora, mas é ser convidado para a reunião" (INGOLD, 2012, p. 27).

Este espaço de transformação e porvir, se relaciona mais ainda à cozinha, quando se considera que, além da presença das pessoas e das relações que acontecem dentro dela, o seu uso efetivo é para preparo de alimentos. Esse é o grande "acontecer" que se dá dentro da cozinha. A comida que se transforma, se movimenta, muda, termina, é reposta, num ciclo interminável de “aconteceres” pelas mãos de pessoas que se revezam neste ambiente desempenhando a função de cozinhar e alimentar. Em metade das respostas é a própria pessoa que respondeu o questionário que cozinha a maior parte das vezes. Nas outras 50\% das vezes, quem cozinha são outras pessoas na casa. Desta forma, a cozinha sempre será diferente a cada vez que se entra nelas, seja: pelo que a cozinha possui estruturalmente, pelos alimentos disponíveis, pelo que está sendo preparado, pelas pessoas que ali trabalham, ou pelos que ali se reúnem. Uma cozinha é sempre diferente todos os dias e pode revelar as mudanças que acontecem nas realidades familiares, nas relações sociais e nas relações de trabalho que ali se estabelecem. 


\section{Considerações finais}

A análise foi feita a partir das relações que acontecem dentro da cozinha e das práticas que nela se constituem no cotidiano das casas. Essa perspectiva se firma por considerar que a cozinha é um local central dentro das moradias. A casa é uma inflexão da ideia de ambiente e um fato social total. A casa é elemento central na nossa vivência e convivência em sociedade. Ela pode ter muitos significados como um local de: história, memória, arquivo, depósito, acolhimento, segurança, estruturação econômica, transformação, troca, vida e morte. Inclusive, pode-se pensar a casa como um local de trabalho, de construção de vida e de cotidiano. Ela pode ser objeto para se pensar inúmeras questões sociais, estruturais e relacionais da sociedade. As relações familiares, de poder, econômicas, políticas, sociais, os modos de vida e de trabalho podem ser configuradas nas casas e na perspectiva a partir das relações que se estabelecem dentro das cozinhas.

A pesquisa que objetivava observar o ambiente, revelou um importante recorte de gênero. As respostas mostraram que as mulheres estão efetivamente mais presentes e inseridas neste ambiente doméstico que os homens. O perfil revelou mulheres urbanas, com boa escolaridade, com emprego formal que participam das rotinas domésticas, cozinhando todos os dias para suas famílias. Um perfil que também ainda reproduz uma realidade geracional, a partir da presença das mães dessas mulheres também nessas atividades. Deste modo, as mudanças dinâmicas que a sociedade apresenta - em certa medida - não estão abrangendo o universo feminino e as mulheres ainda estão acumulando funções e exercendo uma atividade extremamente desvalorizada. O que é ainda mais relevante quando se refere a uma atividade que, de fato, nem é considerada como trabalho.

Olhar para dentro das cozinhas trouxe também a perspectiva das relações sociais que se estabelecem neste ambiente. A cozinha, além de elemento central de convivência, também denota as representações coletivas e as reproduções sociais dos papéis masculinos e femininos no ambiente privado. Somado a isso, as realizações dentro das cozinhas, denotaram o cômodo como essencial para construção material de 
significados e simbolismos que estruturam e moldam os indivíduos e seus modos de vida. Considerando a pluralidade de interações e acontecimentos que são vivenciados dentro da rotina da cozinha das casas entre indivíduos - de dentro e de fora da família - podemos chamar essas relações sociais como um tipo de Sociologia da Cozinha. Mesmo que seja prematuro afirmar, por se tratar de uma pesquisa pouco abrangente, dificilmente será errado considerar que a cozinha é um local de grande aprendizado para entendimento das relações humanas. Por fim, a pesquisa mostra que há um campo que pode ser melhor explorado nos estudos das relações sociais, de gênero e de trabalho - e até de consumo - que se estabelecem a partir da cozinha das casas, indo muito além das relações de parentesco. As relações dentro das cozinhas das casas podem ser utilizadas como ferramentas de análise para melhor compreensão das questões econômicas, de gênero, dominação e divisão sexual do trabalho.

\section{Referências}

BORBA, Clarissa Galvão Cavalcanti. Dos ofícios da alimentação à moderna cozinha profissional: reflexões sobre a ocupação de chef de cozinha / Clarissa Galvão

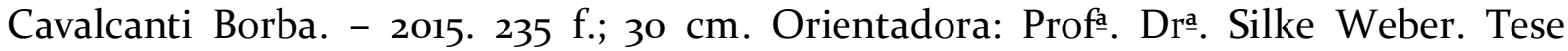
(doutorado) - Universidade Federal de Pernambuco, CFCH. Programa de PósGraduação em Sociologia, Recife, 2015.

BRUSCHINI, C.; LOMBARDI, M. R. Instruídas e trabalhadeiras Trabalho feminino no final do século XX. Cadernos Pagu, Campinas, SP, n. 17-18, p. 157-196, 2016. Disponível em <https://periodicos.sbu.unicamp.br/ojs/index.php/cadpagu/article/view/8644559>. Acesso em: 28 jun. 2019 .

DAVIS, Angela. Mulheres, raça e classe. Tradução: Heci Regina Candiani. - $\mathfrak{1}^{\mathbf{a}}$ ed. São Paulo: Boitempo, 2016.

DOUGLAS, Mary. Pureza e Perigo. Lisboa: Edições 70, 1991.

FEDERICI, Silvia. Calibã e a Bruxa: mulheres, corpo e acumulação primitiva. São Paulo, Elefante, 2017.

GIL, Antônio Carlos. Métodos e Técnicas de Pesquisa Social. 6. ed. São Paulo: Atlas, 2008.

GOOGLE FORMS. Disponível em: <https://www.google.com/intl/pt- 
BR/forms/about/>. Acesso em o5 nov. 2019.

HEREDIA, Beatriz M. A. A Morada da Vida: Trabalho Familiar de Pequenos Produtores do Nordeste do Brasil. Rio de Janeiro: Centro Edelstein de Pesquisas Sociais: Editora Paz e Terra, 2013.

HIRATA, Helena. 2002. Globalização e divisão sexual do trabalho. Cadernos Pagu, Campinas, n. 17-18, $\quad$ p. 139-156. Disponível em $<$ http://www.scielo.br/scielo.php?script=sci_arttext\&pid=So104$83332002000100006 \& \operatorname{lng}=\mathrm{en} \& \mathrm{nrm}=\mathrm{iso}>$. Acesso em 15 ago. 2020.

INGOLD, Tim. 2012. Trazendo as coisas de volta à vida: emaranhados criativos num mundo de materiais. Horizontes Antropológicos, Porto Alegre, v. 18, n. 37, p. 24-44.

MCCALLUM, Cecília; BUSTAMANTE, Vania. Parentesco, gênero e individuação no cotidiano da casa em um bairro popular de Salvador da Bahia. Etnográfica [En ligne], vol. 16 (2) | 2012, mis en ligne le 26 juin 2012, consulté le 27 juin 2021. Disponível em: <http://journals.openedition.org/etnografica/1476>. Acesso em 15 ago. 2020.

McCLINTOCK, Anna. Couro Imperial: Raça, Gênero e Sexualidade no Embate Colonial. Campinas: Editora da Unicamp, 2010.

Registro Civil 2019. IBGE. Sistema de Estatísticas Vitais - Tabelas. Disponível em $<$ https://www.ibge.gov.br/estatisticas/sociais/populacao/911o-estatisticas-do-registrocivil.html?=\&t=resultados $>$. Acessado em 10 jun. de 2020.

SHIVA, Vandana. "Recursos Naturais" (pp. 300-316). In: Sachs, Wolfgang. Dicionário do Desenvolvimento: Guia para o Conhecimento como Poder. Petrópolis: Vozes, 2000

VIEIRA, Isabela. Mulheres trabalham cinco horas a mais e ganham $76 \%$ do salário dos homens. Agência Brasil, o6 dez. 2016. Disponível em <http://agenciabrasil.ebc.com.br/geral/noticia/2016-12/mercado-de-trabalho-continuadiscriminando-mulheres-independentemente-da-crise >. Acesso em o5 dez. 2019. 